\title{
Komunikasi Data Berbasis Protokol UDP pada Sistem Ubiquitous Mobile Sensing Kualitas Sumber Air
}

\author{
Yuning Widiarti*1, Adianto $^{2}$, Mirna Apriani ${ }^{3}$ \\ ${ }^{1,2,3}$ Politeknik Perkapalan Negeri Surabaya; Jalan Teknik Kimia Sukolilo, Surabaya 60111 \\ Telp: (031)5947186, Fax : (031)5942887 \\ e-mail: *11 widy_1109@yahoo.com, ${ }^{2}$ adiantoanditsan@gmail.com, ${ }^{3}$ mirnaapriani@gmail.com
}

\begin{abstract}
Abstrak
Kebutuhan akan monitoring, pengendalian dan evaluasi kualitas air yang efektif dan efisien di perairan daerah Surabaya menjadi tuntutan bagi pertumbuhan populasi, perubahan iklim dan variabilitas di era urbanisasi saat ini. Metode tradisional yang dilakukan dengan mengumpulkan sampel air, menguji dan menganalisis air di laboratorium selama ini relatif mahal dan tidak mempunyai kemampuan pengambilan data secara real time, analisa dan pengiriman informasi yang cepat dalam mengambil keputusan. Disisi lain, penyebaran yang cepat dalam penggunaan ponsel di negara berkembang telah meningkatkan aplikasi manajemen data mobile. Berbagai aplikasi mobile juga meningkat dalam beberapa tahun terakhir. Hal ini dikarenakan harga ponsel yang relatif murah, mudah digunakan dan dapat mengirimkan beberapa jenis informasi termasuk gambar dan data GPS jarak jauh. Pada paper ini penulis memaparkan sistem komunikasi data, sebuah sistem monitoring kualitas sumber daya air berbasis protokol UDP. Sistem ini dinamakan Ubiquitous Mobile Sensing yang terdiri dari mikrokontroler arduino, sensor kualitas air, dan smartphone android yang mempunyai kemampuan mendeteksi temperatur, dissolved oxygen (DO), pH, dan electrical conductivity (EC) secara real time. Dengan sistem monitoring ini diharapkan data yang dihasilkan lebih akurat, cepat dan lebih murah.
\end{abstract}

Kata kunci-protokol UDP, sistem monitoring, ubiquitous mobile sensing

\begin{abstract}
The need for monitoring, effective and efficient control and evaluation of water quality in regional waters Surabaya become a demand for population growth, climate change and variability in the current era of urbanization. The traditional method is done by collecting water samples, test and analyze water in the laboratory has been relatively expensive and do not have the ability to capture real-time data, analysis and information delivery fast in making decisions.On the other hand, the rapid spread in the use of mobile phones in developing countries has increased mobile data management applications. A variety of mobile applications has also increased in recent years. This is because mobile phones cheap, easy to use and can transmit multiple types of information including images and GPS data remotely. In this paper, the author describes a data communication system of water quality resources based on UDP protocol. This system is called ubiquitous mobile sensing consisting of arduino microcontroller, water quality sensors, and android smartphones. It has the ability to detect temperature, dissolved oxygen (DO), pH and electrical conductivity (EC) in real time. By using this monitoring system, the data result is expected to be more accurate, faster and cheaper.
\end{abstract}

Keywords-UDP protocol, monitoring system, ubiquitous mobile sensing

Received October $24^{\text {th }}, 2016$; Revised January $4^{\text {th }}$, 2017; Accepted January $27^{\text {th }}, 2017$ 


\section{PENDAHULUAN}

Surabaya adalah ibu kota propinsi Jawa Timur yang merupakan kota terbesar kedua di Indonesia dengan jumlah penduduk 2.711.090 jiwa (data BP3S Kota Surabaya). Jumlah tersebut akan semakin meningkat sejalan dengan pertumbuhan kota Surabaya sebagai kota metropolitan, sehingga hal ini berdampak pada kebutuhan terhadap prasarana dan sarana penunjang perkotaan. Peningkatan kebutuhan air bersih mendorong manusia untuk berusaha meyediakan air bersih dengan standar kualitas dan kuantitas, dalam arti luas peningkatan jumlah penduduk dan aktifitas sosial berpengaruh pada peningkatan kebutuhan akan air bersih[1].

Kota Surabaya semakin hari semakin berkembang dimana pemukiman, industri dan fasilitas-fasilitas lain yang banyak dibangun juga mengalami masalah penyediaan air bersih. Pemerintah Kota Surabaya mentargetkan memiliki instalasi air siap minum pada 2019, dimana kualitas air bersih serta sistem distribusi air yang baik dapat dirasakan oleh seluruh rumah tangga di Surabaya dan juga Pemerintah Indonesia, melalui Kementerian Pekerjaan Umum mengakui dibutuhkan anggaran yang cukup besar untuk memenuhi kebutuhan air bersih dan sanitasi sehat sesuai target universal akses pada 2019.Untuk itu diperlukan usaha yang terus menerus untuk meningkatkan akses di bidang air dan sanitasi, khususnya di 10 tahun terakhir sejalan dengan komitmen pemerintah memenuhi target MDG's yakni berkurangnya setengah jumlah penduduk yang tidak terlayani air minum dan sanitasi yang layak pada 2015 ini. Namun terdapat tantangan yang harus dihadapi antara lain: penduduk yang tersebar dan sebagian tinggal di pulau-pulau terpencil, dan juga persoalan pertambahan penduduk dan perubahan iklim, peningkatan urbanisasi dan perkembangan ekonomi yang bertumbuh dengan baik sehinga menyebabkan peningkatan kebutuhan air dan energi, termasuk bertambahnya limbah dan polusi. Monitoring dan evaluasi kualitas air menjadi sesuatu yang sangat penting dalam pengelolaan dan pemanfaatan sumber daya air yang berkelanjutan [2].Hal ini menjadi sesuatu yang menarik bagi para peneliti dan perhatian pemerintah meskipun di sebagian besar daerah di Indonesia, seperti di Surabaya monitoring dan evaluasi kualitas air dilakukan secara manual. Pendekatan secara manual ini dilakukan dengan membawa sampling air ke laboratorium dan mengujinya. Analisis yang dilakukan memerlukan biaya yang mahal, waktu yang lama dan resolusi yang rendah.

Selama beberapa tahun terakhir, ubiquitous mobile sensing (UMS) telah banyak menerima perhatian baik di bidang lingkungan, industri monitoring maupun aplikasi pengendalian. UMS juga memberikan keuntungan yang banyak dari segi pembiayaan maupun kecerdasan terdistribusi. Di lain pihak biaya instalasi dan pemeliharaan berkurang karena penggunaan perangkat murah yang tidak memerlukan kabel, hal inilah yang merupakan alasan mengapa teknologi UMS telah menarik perhatian dan berkembang pesat di kalangan akademisi dan industri. Teknologi ini dapat benar-benar diterapkan dalam monitoring dan evaluasi kualitas air.

Saat ini jaringan sensor nirkabel (JSN) telah menerima banyak perhatian di lingkungan sistem monitoring dan kontrol untuk aplikasi industri. Untuk menjadi salah satu bagian utama dalam sistem cerdas, JSN telah memberi keuntungan yang signifikan baik dalam biaya maupun kecerdasan terdistribusi [3]. Peneliti-peneliti sebelumnya telah banyak menyumbangkan hasil karya ilmiahnya diantaranya: Chaamwe [4] menekankan fakta bahwa WSNs cocok untuk pemantauan kualitas air. Dalam penelitiannya yang berjudul On the Design of a Water Quality Wireless Sensor Network (WQWSN): An Application to Water Quality Monitoring inMalawi pada tahun 2009 Zennaro, dkk mengusulkan desain JSN untuk sistempemantauan kualitas air [5]. Mereka menggunakan Sun motes SPOT dan sensor 90-FLT seri E untuk mengukur pH air, konduktivitas, jumlah garam terlarut (TDS), oksigen terlarut (DO), kekeruhan dan suhu. Biaya sistem yang diusulkan sekitar US \$ 3.400. Namun solusi yang ditawarkan tidak cocok untuk jangka panjang di lingkungan luar (outdoor). Dengan menggunakan kontroler ARM, Kumar et al. [6] menampilkan sistem pemantauan kualitas air berbasis JSN tenaga surya untuk mengukur pH air, tingkat oksigen dan kekeruhan. Selanjutnya, Aravinda et al. [7] menyajikan sistem

IJCCS Vol. 10, No. 2, July $2016: 219-228$ 
monitoring parameter fisik-kimia air secara nirkabel dan murah menggunakan Arduino Mega 2560. Mereka mengukur $\mathrm{pH}$, DO, konduktivitas potensial reduksi oksidasi, cahaya dan suhu air. Penulisnya melaporkan bahwa sistem membutuhkan biaya sekitar US \$ 1.040. Namun, pendekatan mereka menggunakan komputer sebagai gateway yang mahal.

Pada paper ini penulis mengusulkan pembuatan sebuah sistem UMS untuk pemantauan kualitas air. Sistem yang terdiri dari mikrokontroler arduino, satu set sensor kualitas air dan smartphone android ini menyajikan visualisasi data dari UMS yang secara mudah dapat digunakan oleh pengguna tanpa menginstal perangkat lunak tertentu. Selain itu, prototipe ini sesuai digunakan untuk lingkungan outdoor dan dapat digunakan dalam jangka panjang.

\section{METODE PENELITIAN}

Sistem monitoring yang diusulkan dan dikembangkan dalam penelitian ini memiliki tujuan sebagai sarana untuk membantu pihak PDAM dalam mengelola sumber air di perairan wilayah Surabaya. Sistem ini merupakan sebuah inovasi teknologi yang terintegrasi untuk menghadapi permasalahan kualitas air bersih di kota Surabaya yang pengerjaannya terdiri dari tiga pekerjaan utama yaitu: pengerjaan unit sensor, komunikasi dari unit sensor ke data center, dan komunikasi dari data center ke smatphone android. Untuk mempermudah pengerjaan penelitian ini, maka perlu digambarkan diagram alir pengerjaan penelitian seperti pada Gambar 1.

\subsection{Desain Sistem}

Desain untuk sistem monitoring kualitas sumber air dengan smartphone di lokasi penginderaan dan pelaporan data diusulkan pada penelitian ini dikembangkan sebagai salah satu sarana untuk peningkatan pengelolaan air bersih di Surabaya. Sistem pada penelitian ini terdiri dari empat komponen utama, yaitu: 1) satu set perangkat sensor kualitas air yang terdiri dari mikrokontroler arduino dan sensor unit, 2) modul komunikasi yang menghubungkan perangkat sensor dan smartphone 3) aplikasi mobile yang dikembangkan menggunakan platform android, dan 4) Data center. Mikrokontroler arduino adalah perangkat kontrol utama yang mengendalikan dan melakukan tindakan yang diperlukan oleh sistem. Unit sensor terdiri dari beberapa sensor yang digunakan untuk mendeteksi beberapa parameter kualitas air. Pada prototipe ini terdapat 4 sensor untuk mengukur $\mathrm{pH}, \mathrm{EC}, \mathrm{DO}$, dan temperatur yang merupakan karakteristik umum dari kualitas air. Sensor dan modul komunikasi secara langsung dihubungkan ke kontroler utama. Mikrokontroler Arduino berkomunikasi dengan smartphone android melalui modul bluetooth serial. Kemudian smartphone android akan mengirimkan data melalui internet dalam bentuk jaringan Virtual Private Network (VPN) ke Data Center monitoring sumber air. Arsitektur sistem seperti ditunjukkan pada Gambar 2.

\subsection{Perencanaan Perangkat Sensor}

Perangkat sensor terdiri dari mikrokontroler Arduino, unit sensor dan power supply. Sensor unit seperti ditunjukkan pada Gambar 3, terdiri dari beberapa sensor yang digunakan untuk mendeteksi parameter kualitas air, yaitu sensor $\mathrm{pH}$, sensor konduktivitas listrik (EC), DO dan temperatur. Sensor EC, pH, dan DO diinterface dengan mikrokontroler kecuali sensor temperatur yang secara langsung dihubungkan dengan mikrokontroler Arduino. Sensor-sensor tersebut dikalibrasi secara akurat agar dapat digunakan dengan benar. 


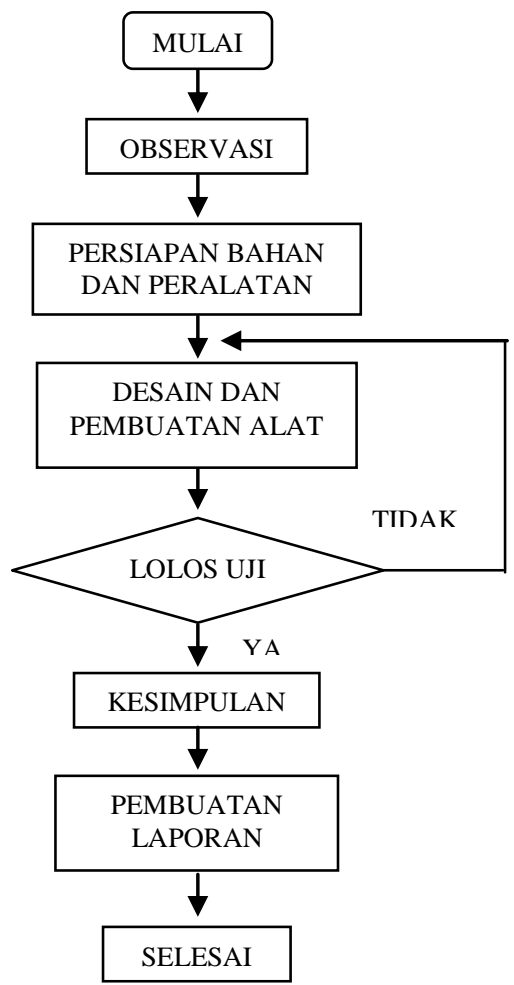

Gambar 1 Diagram Alir Pengerjaan
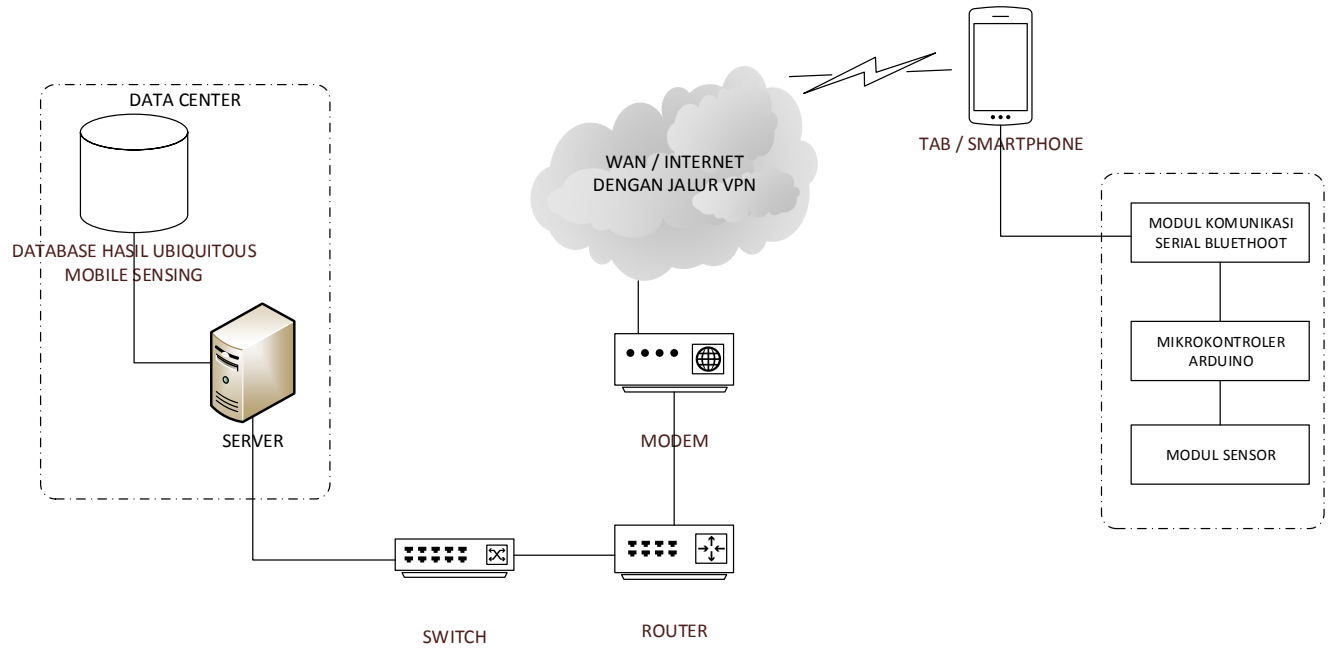

Gambar 2 Arsitektur Sistem 


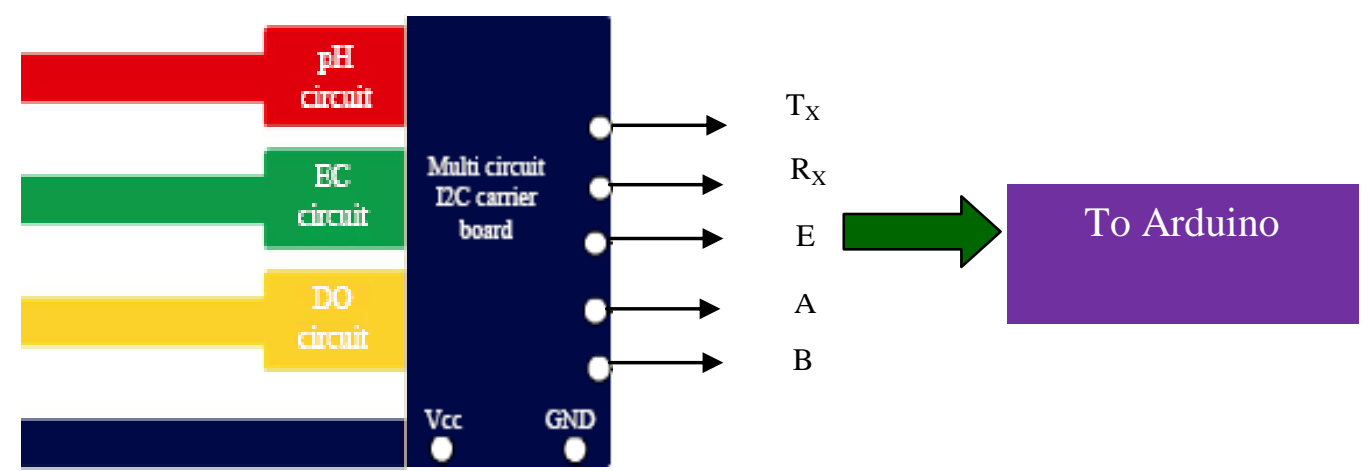

Gambar 3 Sensor Unit

\subsection{Modul Komunikasi yang Digunakan}

Modul bluetooth serial digunakan untuk menyediakan komunikasi antara perangkat sensor dan smartphone android. Banyak smartphone saat ini memiliki kemampuan untuk berkomunikasi menggunakan bluetooth. Modul bluetooth dapat dengan mudah digunakan dengan arduino untuk komunikasi serial nirkabel. Modul ini memiliki dua mode, yaitu: perangkat master dan slave yang dikonfigurasi untuk beroperasi dalam modus master.

\subsection{Perangkat Jaringan}

Perangkat jaringan yang akan dipakai pada penelitian ini meliputi modem untuk menerima data dari WAN/INTERNET dalam hal ini akan melalui jalur VPN. Untuk mendesain jalur VPN sendiri memerlukan perangkat Router. Perangkat Router ini memiliki fungsi membuat jalur khusus dengan smartphone yang melewati jaringan internet. Jalur khusus yang dibentuk ini memiliki fungsi seperti pipa. Sehinggga data yang dikirimkan dari perangkat smartphone android akan cepat dan aman. Dari router ini data akan disimpan dalam data center. Alur kerja ubiquitous mobile sensing (UMS) ditunjukkan pada Gambar 4.

\section{HASIL DAN PEMBAHASAN}

Pemegang peranan penting dalam UMS ini adalah penggunaan wireless sensor node[8]. Data parameter air yang terdiri dari: data temperatur, $\mathrm{pH}, \mathrm{DO}$ dan $\mathrm{EC}$ diperoleh dari unit sensor yang secara langsung kontak dengan sumber air. Data yang diperoleh kemudian diproses oleh mikrokontroller arduino. Data sensor yang telah diproses pada mikrokontroller dikirimkan ke smartphone Android dalam bentuk serial melalui modul bluetooth. Proses pengiriman data dari mikrokontroller ke smartphone dapat dilakukan secara otomatis jika ada pairing antar modul bluetooth. Proses pengiriman datanya dapat ditunjukkan seperti pada Gambar 5. 


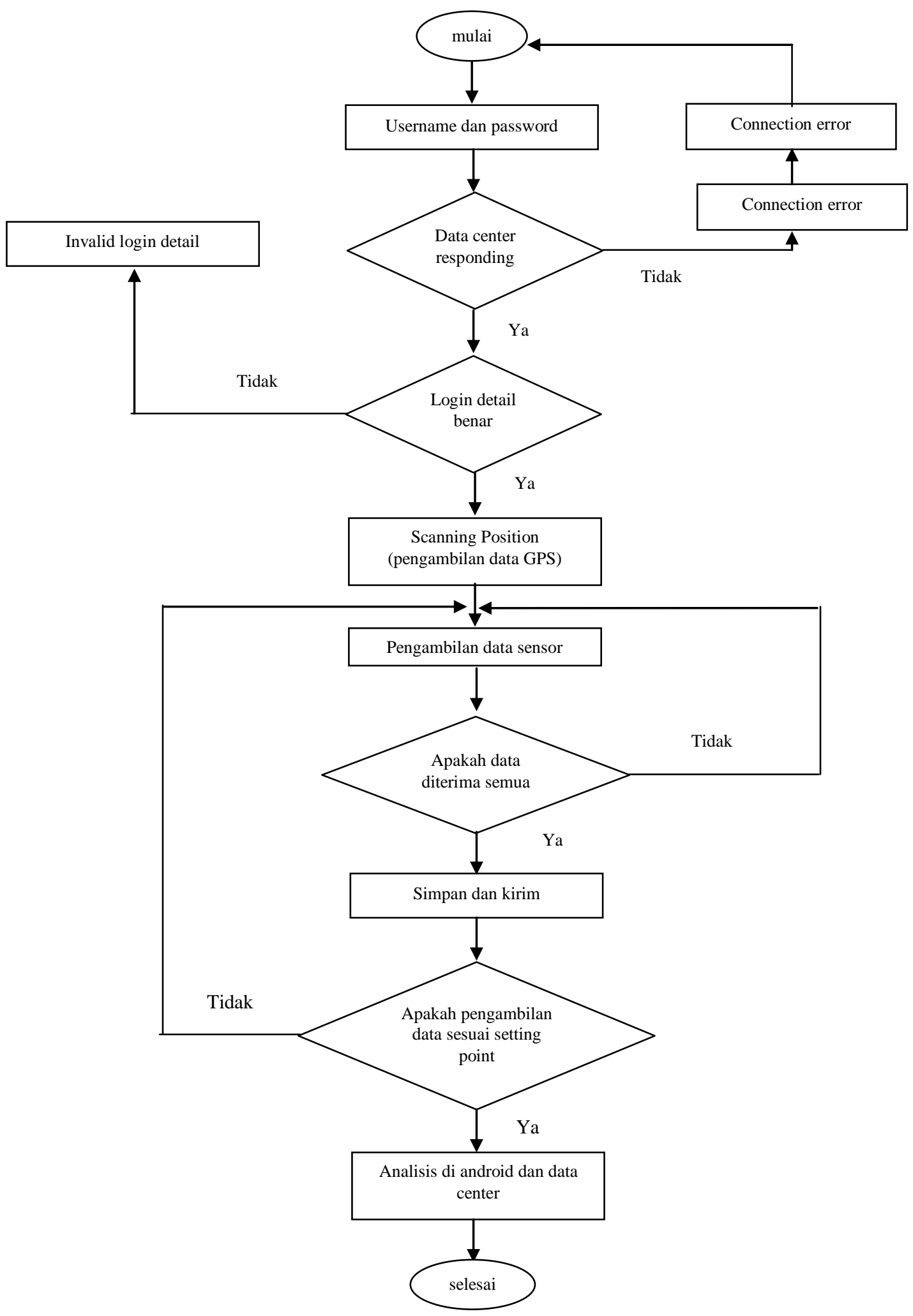

IJCCS Vol. 10, No. 2, July 2016 : 219 - 228 
Gambar 4 Flowchart / Alur Kerja Ubiquitous Mobile Sensing (UMS) System
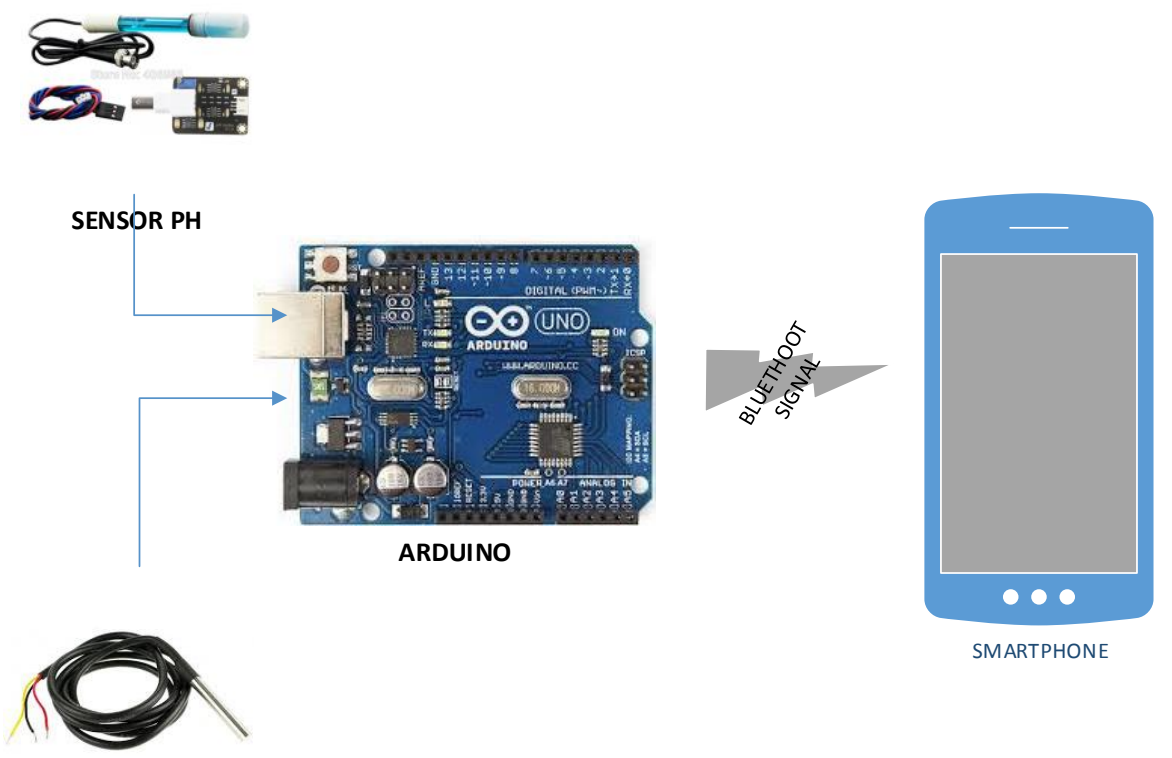

SENSOR SUHU

Gambar 5 Aliran Komunikasi DataUnit Sensor dengan Smartphone Android

Data sensor yang diperoleh pada komunikasi serial mendapatkan penambahan data tanggal dan waktu dari perangkat smartphone. Selanjutnya melalui protokol UDP data sensor dikirimkan ke data center dengan jawaban data telah diterima dengan benar di data center. Skenario penelitian ini menggunakan protokol UDP yang bersifat connectionless dimana pesanpesan UDP akan dikirimkan tanpa harus dilakukan proses negosiasi koneksi antara dua host yang hendak bertukar informasi [9]. Pada percobaan sebelumnya penulis menggunakan komunikasi connection oriented dengan menggunakan TCP Protocol dengan provider yang lain, namun proses ini tidak diijinkan dari pihak provider seluler sehingga pengiriman data dari smartphone ke data center tidak dapat dilakukan. Dengan menggunakan provider yang sama juga terkendala dengan masalah jenis layanan provider seluler, dimana pengiriman data harus dengan menggunakan layanan 4G. Selanjutnya penulis menggunakan mode connectionless yang dimodifikasi dengan pemberian notifikasi apabila data telah terkirim di data center. Penerimaan data sensor pada smartphone ditunjukkan seperti pada Gambar 6.

Data sensor yang dikirimkan dari smartphone ke data center menggunakan aplikasi server yang berfungsi untuk memisahkan data yang selanjutnya dikirim ke database. Proses pemisahan dan pengiriman data tersebut menggunakan program Node Js. Node Js adalah program varian yang merupakan pengembangan program javascript [10]. Proses penerimaan data server yang ditangani oleh Node Js dapat ditunjukkan seperti pada Gambar 7.

Data yang diterima di server meliputi: data tanggal,waktu,posisi, temperatur, $\mathrm{pH}$, sensor oksigen dan kadar salinitas (EC). Selanjutnya data tersebutdiaplikasikanpada MySql. Pada saat yang bersamaan, data yang ditampilkan pada web sesuai dengan data waktu yang dikirimkan ke datacenter (realtime), seperti terlihat pada Gambar 8. 


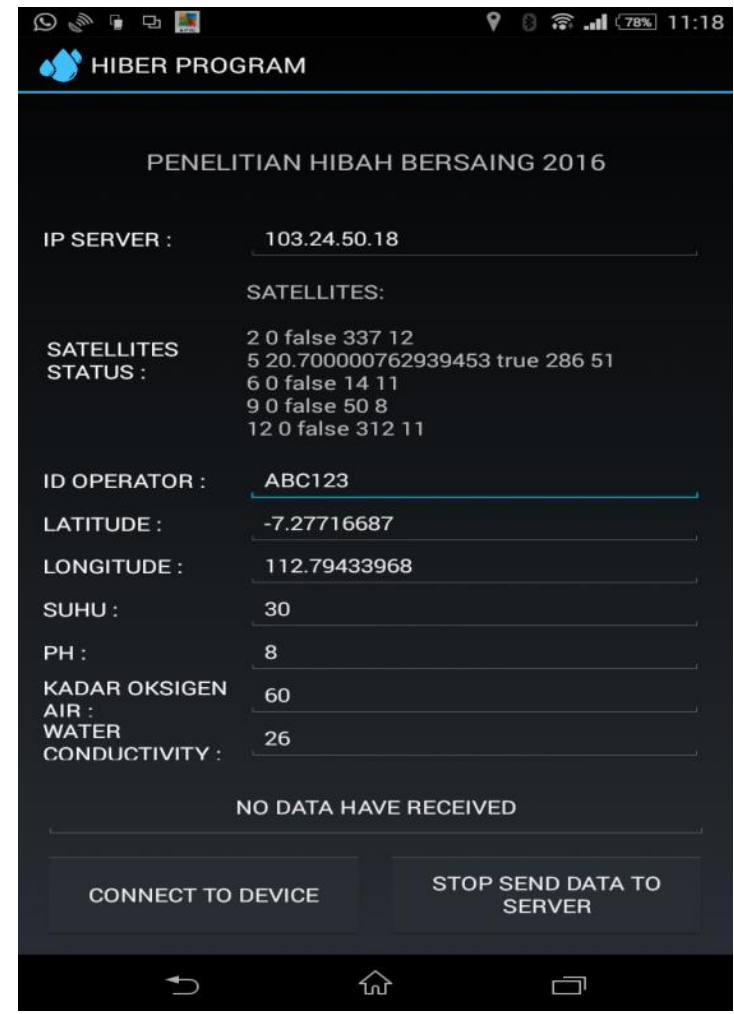

Gambar 6 Interface Program Android Penerimaan Data dari Unit Sensor

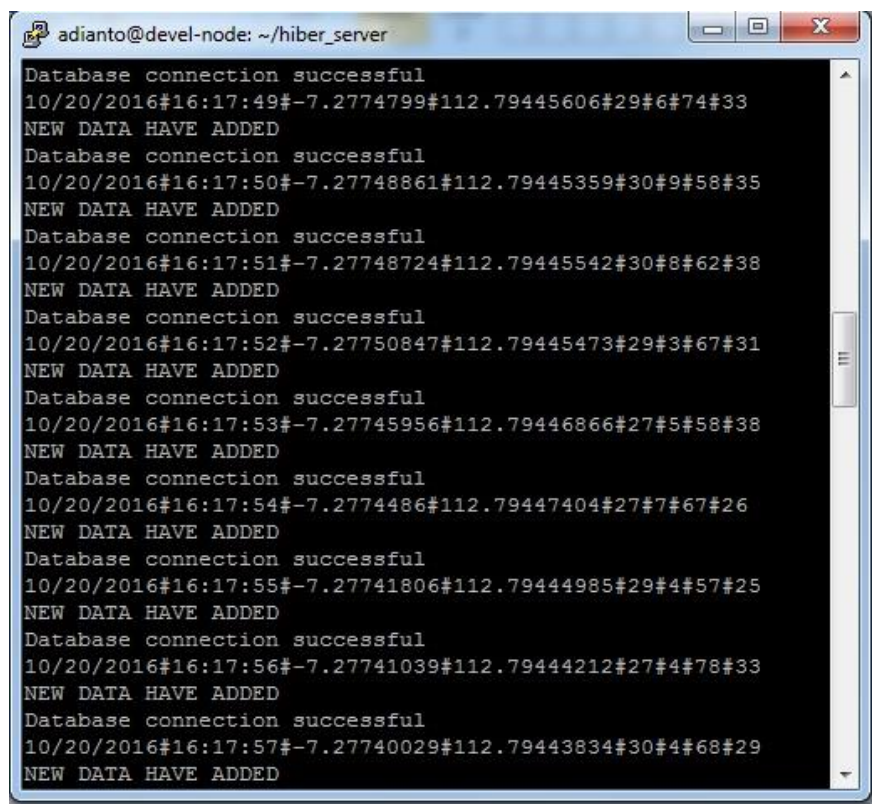

Gambar 7 Bentuk Data yang Diterima Aplikasi Server 


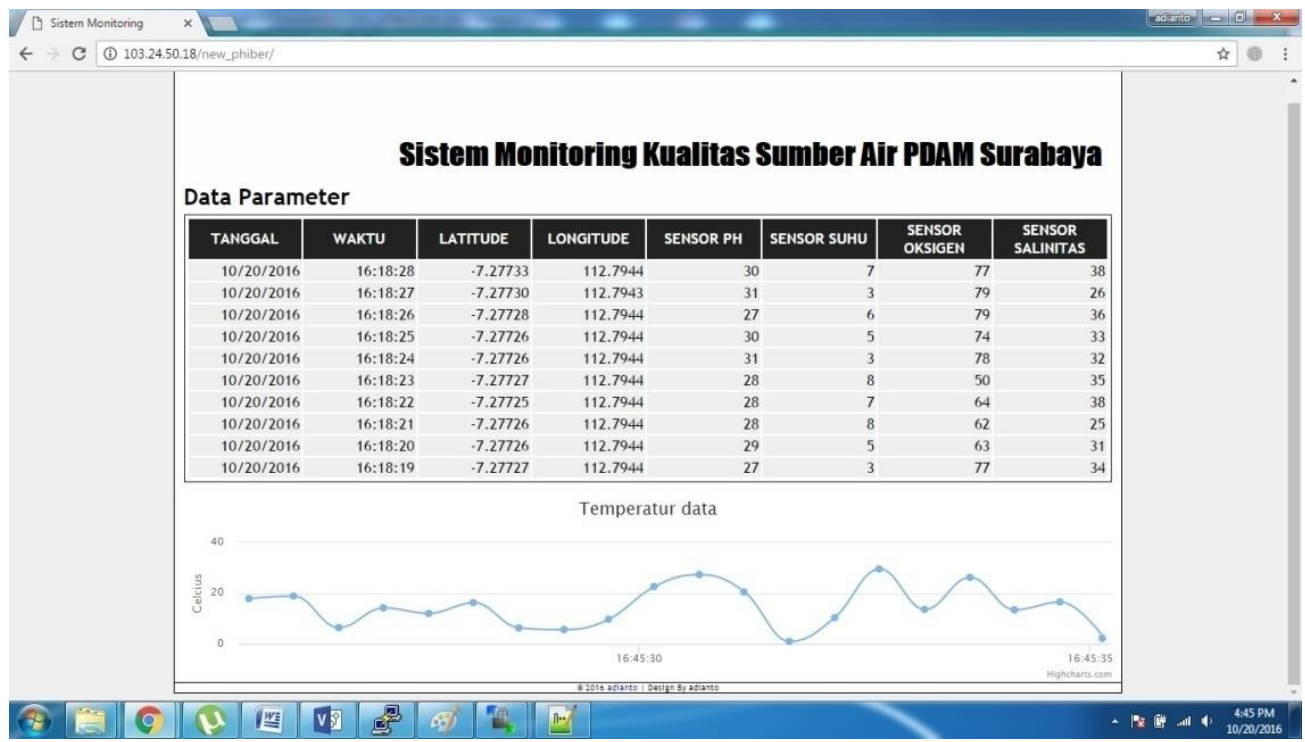

Gambar 8 Tampilan Data Monitoring

\section{KESIMPULAN}

Dari tahap kegiatan penelitian yang telah dilakukan, maka diperoleh kesimpulan sebagai berikut:

1. Proses penyimpanan data dari smartphone android ke datacenter efektif dilakukan dengan menggunakan program database server MySQL.

2. Pemilihan jenis protokol komunikasi data harus memperhatikan kecepatan dan keakurasian data yang diperoleh, dimana pada penelitian ini peneliti memilih menggunakan pemrograman socket dengan protokol UDP sebagai protokol pengiriman data dan menggunakan protokol http.

3. Untuk implementasi tampilan di web dengan menggunakan PHP, JQuery dan AJAX dengan tujuan dapat memonitor dengan cepat data yang telah diperoleh dalam database MySQL tanpa loading data yang lama.

4. Proses penyimpanan data melalui jaringan wireless dengan jalur data LTE juga harus mempertimbangkan datacenter yang digunakan karena berkaitan dengan regulasi tiap operator yang membolehkan komunikasi data wireless berbasis socket dengan protokol UDP.

5. Penggunaan penyimpanan data internal untuk mengatasi gangguan komunikasi data dengan mengunakan jaringan data LTE Telkomsel

\section{SARAN}

1. UMS dapat direalisasikan dengan baik menggunakan multi komunikasi data dengan komunikasi wireless jaringan data LTE berbagai operator.

2. Optimasi sistem dapat diwujudkan dengan menggunakan machine learning sebagai metode pengambilan keputusan dari data pengujian.

\section{UCAPAN TERIMA KASIH}

Penulis mengucapkan terima kasih kepada Direktorat Riset dan Pengabdian Masyarakat (DRPM) yang telah memberikan pendanaan dalam pelaksanaan program penelitian Hibah Bersaing Tahun 2016, Politeknik Perkapalan Negeri Surabaya sebagai institusi yang telah banyak memberikan dukungan sarana dan prasarana demi terselesaikannya penelitian dan 
PDAM yang telah memberikan dukungan dan kerjasama yang baik dalam kegiatan penelitian ini.

\section{DAFTAR PUSTAKA}

[1]Setiawan, M. Ikhsan, Study Pemenuhan Kebutuhan Air Bersih PDAM Kota Surabaya Tahun Proyeksi (2015)

[2]Faustine, A., Mvuma , Aloys N., Mongi, Hector J., Gabriel, Maria C., Tenge, Albino J., Kucel, Samuel B.Wireless Sensor Networks for Water Quality Monitoring and Control within Lake Victoria Basin: Prototype Development

[3]Losilla, F., Garcia-Sanchez, A.-J., Garcia-Sanchez, F., Garcia-Haro, J. and Haas, Z.J. (2011) A Comprehensive Approachto WSN-Based ITS Applications. Sensors, 11, 10220-10265. http://dx.doi.org/10.3390/s111110220

[4]Chaamwe, N., Liu, W. and Jiang, H. (2010) Wireless Sensor Networks in the Context of Zambia: A Developing Country. 2010 Second International Conference on Information Technology and Computer Science (ITCS), Kiev, 24-25 July2010, 474-478. http://dx.doi.org/10.1109/ITCS.2010.122

[5]Zennaro, M., Floros, A., Dogan, G., Sun, T., Cao, Z., Huang, C., Bahader, M., Ntareme, H. and Bagula, A. (2009) On the Design of a Water Quality Wireless Sensor Network (WQWSN): An Application to Water Quality Monitoring in Malawi. 2009 International Conference on Parallel Processing Workshops, Vienna, 22-25 September 2009, 330336.http://dx.doi.org/10.1109/ICPPW.2009.57

[6] Kumar, R.K., Mohan, M.C., Vengateshapandiyan, S., Kumar, M.M. and Eswaran, R. (2014) Solar Based Advanced Water Quality Monitoring System Using Wireless Sensor Network. International Journal of Science, Engineering andTechnology Research (IJSETR), 3, 385389.

[7] Rao, A.S., Marshall, S., Gubbi, J., Palaniswami, M., Sinnott, R. and Pettigrove, V. (2013) Design of Low-Cost Autonomous Water Quality Monitoring System. 2013 International Conference on Advances in Computing, Communicationsand Informatics (ICACCI), Mysore, 22-25 August 2013, 14-19.

[8] Dabiri,F., Encarnacao A., Sarrafzadeh, M., Jafari R., Zahoory A., Noshadi H., "Wireless Sensor Networks for Health Monitoring", Mobile and Ubiquitous Systems, Annual International Conference on, vol. 00, no. , pp. 479-781, 2005, doi:10.1109/MOBIQUITOUS.2005.65

[9]Zhang, Y. B., Zhang Z. B., Zhao Y., Guo L., Analysis and Research on TCP and UDP Network Traffic[J]. Application Research of Computer, 2010

[10]Carter B., "HTML Educational Node.js System (HENS): An Applied System for Web Development", , vol. 00, no. , pp. 27-31, 2014, doi:10.1109/GOCICT.2014.25 